JMK: JURNAL MEDIA KESEHATAN

P-ISSN : 1979-5750

E-ISSN: 2654-5705

\title{
PENGGUNAAN HANDUK, KEBIASAAN MENGGIGIT KUKU JARI TANGAN TERHADAP KEJADIAN INFEKSI Soil Transmitted Helminth (STH) PADA ANAK PANTI ASUHAN DI JAYAPURA
}

\author{
Risda Hartati ${ }^{1)}$, Novianti Yoyo Simega ${ }^{1)}$, Meidy J. Imbi ${ }^{1)}$, Indra Taufik Sahli ${ }^{1)}$, Asrianto ${ }^{1)}$ \\ ${ }^{1}$ Jurusan Teknologi Laboratorium Medis, Poltekkes Kemenkes Jayapura, Papua \\ E-mail: risdahartati@gmail.com
}

\begin{abstract}
Problem: Helminthiasis is generally caused by the group of Soil Transmitted Helminth (STH) worms, namely Ascaris lumbricoides, Trichuris trichiura and hookworm. Worms have an impact on health problems such as diarrhea, malnutrition and anemia. Risk factors for helminthic infection including poor personal hygiene care, nail biting habits, the habit of not wearing footwear, contact with soil media, will increase the transmission of eggs that inhabit the intestines. The Aim Of The Research: To determine the prevalence of helminthiasis and risk factors for STH intestinal worms in children living in an orphanage in Jayapura. Research Method: Fecal samples were collected from orphanage children $(n=63)$ using saturated salt solution to detect the presence of STH worm eggs between months August-October 2020. The Results: The prevalence of STH worm infection in orphanages in Jayapura was $12.69 \%$ in the highest age group, 6-11 years old with Ascaris lumbricoides, Trichuris trichiura and hookworm infections. The dominant risk factors represented among the most infected children include sharing of towels, the habit of biting fingernails and the habit of not wearing footwear while playing were very significant factors for the incidence of STH worm infection $(\mathrm{p}<0.05)$. Conclusion: The prevalence of STH worm infection in orphanage children in Jayapura was $12.69 \%$ in the highest age group 6-11 years with the most dominant risk factors are the habit of not wearint footwear while playing, the habit of biting fingernails and sharing towel together.
\end{abstract}

Keywords: infection, STH, risk factors

ABSTRAK

Permasalahan:Infeksi kecacingan umumnya oleh kelompok cacing Soil Transmitted Helminth (STH) yaitu Ascaris lumbricoides, Trichuris trichiura dan hookworm. Kecacingan berdampak pada masalah kesehatan seperti diare, malnutrisi dan anemia. Faktor risiko dari infeksi helminthiasis termasuk kebersihan dan perawatan personal higiene yang buruk, perilaku seperti menggigit kuku, tidak menggunakan alas kaki pada saat bermain dan menggunakan media tanah pada saat bermain dapat meningkatkan transmisi sel telur yang berhabitat di usus. Tujuan Penelitian:Untuk mengetahui prevalensi infeksi kecacingan dan faktor risiko kecacingan usus STH pada anak yang tinggal di panti asuhan di Jayapura.Metode Penelitian: Sampel feses dikumpulkan dari anak panti asuhan $(n=63)$ menggunakan larutan garam jenuh untuk mendeteksi keberdaan telur cacing STH antara Bulan Agustus - Oktober Tahun 2020.Hasil: Prevalensi infeksi kecacingan STH pada anak panti asuhan di Jayapura sebesar 12,69\% pada kelompok umur tertinggi yaitu 6-11 tahun dengan infeksi cacing Ascaris lumbricoides, Trichuris trichiura dan hookworm. Faktor risiko yang dominan diwakili paling banyak pada anak yang terinfeksi dibandingkan dengan yang tidak terinfeksi yaitu menggunakan handuk secara bersama-sama, kebiasaan menggigit kuku jari tangan dan tidak menggunakan alas kaki pada saat bermain merupakan faktor yang sangat signifikan dari kejadian infeksi kecacingan STH ( $<$ 0.05).Kesimpulan: Prevalensi infeksi kecacingan STH pada anak panti asuhan di Jayapura sebesar $12,69 \%$ pada kelompok umur tertinggi 6 - 11 tahun dengan faktor risiko yang paling dominan yaitu tidak menggunakan alas kaki pada saat bermain, kebiasaan menggigit kuku jari tangan dan menggunakan handuk secara bersama-sama.

Kata Kunci: Infeksi, STH, Faktor Risiko 


\section{PENDAHULUAN}

Infeksi parasite usus tersebar luas di seluruh dunia. Angka kematian dan kesakitan sangat signifikan terutama di negara berkembang salah satunya Indonesia. Infeksi terutama melalui konsumsi air, tanah (soil transmitted helminth) atau makanan yang terkontaminasi oleh feses yang mengandung kista, telur maupun larva cacing (Sah et al., 2013). Jenis cacing yang dimaksud adalah cacing gelang (Ascaris lumbricoides), cacing cambuk (Trichuris trichiura) dan cacing tambang (Ancylostoma duodenale dan Necator americanus). Berbagai faktor yang dapat mempengaruhi kejadian infeksi kecacingan sangat erat hubungannya dengan higiene dan sanitasi individu antara lain; kebersihan diri seperti memakai alas kaki, mencuci tangan dengan sabun, kebiasaan memotong kuku merupakan beberapa cara dalam pencegahan penularan infeksi kecacingan (Bethony et al., 2006).

Menurut World Health Organization (WHO) 2017 lebih dari 1,5 milyar orang atau $24 \%$ dari populasi dunia mengalami infeksi kecacingan STH, dan lebih dari 870 juta anak hidup di lingkungan yang penularannya sangat intensif dan membutuhkan pengobatan akibat parasit ini. Prevalensi kejadian infeksi kecacingan di Indonesia pada anak diperkirakan 2,7-60,7\%. Kelompok usia terbanyak yang terinfeksi pada usia 6-12 tahun atau pada tahapan usia anak sekolah dasar, dengan jumlah 189 juta anak.

Dinas Kesehatan Provinsi Papua pada tahun 2011 melaporkan infeksi kecacingan sebanyak 528,8 kasus infeksi per 1.000 penduduk dan 2,48 kasus per 1.000 penduduk dilaporkan terjadi di Kota Jayapura (Martila et al., 2016). Faktor risiko infeksi cacing usus seperti personal higiene yang buruk, penyimpangan perilaku seperti mengisap jari tangan, menggigit kuku, bermain tanah dapat mendukung terjadinya penularan telur cacing usus dari satu individu ke individu lain terutama pada anak-anak yang tinggal dalam suatu kelompok komunitas tertutup atau dalam suatu lembaga sosial seperti panti asuhan (Du \& Vo, 2012).

Anak panti asuhan merupakan anak yang kehilangan orang tuanya oleh karena meninggal baik itu ayah atau ibu atau keduanya dan juga anak yang ditinggalkan oleh orang tuanya dan orang tuanya tidak dapat dipastikan keberadaannya (Waterston, 2011). Diperkirakan terdapat 8 Lembaga Kesejahteraan Sosial Anak (LKSA) atau Panti Asuhan 
yang terletak di Kota Jayapura dan Kabupaten Jayapura, dan tidak adanya data yang dipublikasikan mengenai prevalensi infeksi kecacingan usus pada anak yang tinggal di panti asuhan di Kota Jayapura maupun Kabupaten Jayapura. Oleh karena itu perlu dilakukan identifikasi dan pendokumentasian terhadap prevalensi dan berbagai faktor risiko infeksi kecacingan soil transmitted helminth.

\section{METODE PENELITIAN}

Penelitian ini merupakan penelitian deskriptif dengan desain cross sectional study. Penelitian dilakukan pada bulan Agustus - Oktober tahun 2020 pada tiga panti asuhan yang ada di Kota Jayapura dan Kabupaten Jayapura. Pertemuan pendahuluan dilakukan kepada ketua pengelola panti asuhan dengan menjelaskan secara terperinci maksud dan tujuan penelitian. Persetujuan penelitian ditanda tangani oleh pengelola panti asuhan untuk anak panti asuhan usia antara 0-5 tahun dan anak panti asuhan dengan usia sekolah dasar maupun menengah atas.

Proses pengambilan sampel feses dijelaskan dengan jelas kepada pengelola panti asuhan dan anak panti asuhan yaitu dengan menggunakan lidi atau sendok es krim yang terbuat dari kayu dengan pot sampel yang tertutup ulir yang selanjutnya diberi label nomor urut sesuai dengan nomor identifikasi yang diberikan kepada setiap pengelola panti asuhan.

Sampel feses yang dikumpulkan setiap pagi dari masing-masing anak diperiksa di laboratorium parasitologi Poltekkes Kemenkes Jayapura dengan metode konsentrasi sedimentasi dan flotasi menggunakan larutan garam jenuh (Healy, 1996)

Analisis data menggunakan uji Chi-Square dan uji regresi logistik ganda untuk menganalisis faktor paling beresiko terhadap kejadian infeksi kecacingan pada anak panti asuhan. Tingkat signifikan setiap uji ditetapkan pada nilai $\mathrm{p}<0.05$.

\section{HASIL}

Hasil pemeriksaan sampel tinja anak panti asuhan ditunjukkan pada Tabel 1 dari 63 jumlah total sampel yang diperiksa sebanyak $8(12,69 \%)$ anak terinfeksi cacing dan sebanyak $55(87,30 \%)$ anak tidak terinfeksi cacing. Prevalensi anak yang mengalami infeksi STH sebesar 12,69\% dengan keadaan infeksi tunggal dan infeksi ganda. 
Tabel 1 Prevalensi Infeksi Kecacingan Anak Panti Asuhan di Jayapura Tahun 2020

\begin{tabular}{|c|c|c|c|c|c|}
\hline \multirow[b]{2}{*}{$\begin{array}{c}\text { Kode Panti } \\
\text { Asuhan }\end{array}$} & \multirow[b]{2}{*}{$\begin{array}{l}\text { Jumlah } \\
\text { Sampel }\end{array}$} & \multicolumn{3}{|c|}{ Jumlah Positif } & \multirow[t]{2}{*}{$\begin{array}{c}\text { Total } \\
(\%)\end{array}$} \\
\hline & & $\begin{array}{c}\text { Ascaris } \\
\text { lumbricoides } \\
(\%)\end{array}$ & $\begin{array}{c}\text { Trichuris } \\
\text { trichiura } \\
(\%)\end{array}$ & Hookworm & \\
\hline $\bar{A}$ & 19 & $2(10,2)$ & $1(5,26)$ & $1(5,26)$ & $4(28,57)$ \\
\hline B & 21 & $1(4,76)$ & $1(4,76)$ & $0(0,0)$ & $2(9,52)$ \\
\hline $\mathrm{C}$ & 23 & $1(4,35)$ & $1(4,35)$ & $0(0,0)$ & $2(8,69)$ \\
\hline Total & 63 & $4(6,34)$ & $3(4,76)$ & $1(1,59)$ & $8(12,69)$ \\
\hline
\end{tabular}

Tabel 2 menunjukkan hasil prevalensi infeksi STH pada anak panti asuhan dengan kelompok umur terbanyak yaitu 6 - 11 tahun dengan jumlah infeksi sebanyak $6(17,1 \%)$ ditemukan cacing Ascaris lumbricoides, Trichuris trichiura dan hookworm. Pada kelompok umur 0 - 5 tahun sebanyak 2 (33,3\%) dengan infeksi cacing Ascaris lumbricoides dan Trichuris trichiura.

Tabel 2. Prevalensi Infeksi Kecacingan STH Anak Panti Asuhan Berdasarkan Kelompok

\begin{tabular}{cccccc}
\hline \multicolumn{7}{c}{$\begin{array}{c}\text { Usia } \\
\text { Umur }\end{array}$} & Jumlah & Sampl & $\begin{array}{c}\text { Ascaris } \\
\text { Uumbricoides }\end{array}$ & $\begin{array}{c}\text { Trichuris } \\
\text { trichiura } \\
(\boldsymbol{\%})\end{array}$ & Hookworm & $\begin{array}{c}\text { Total } \\
(\boldsymbol{\%})\end{array}$ \\
\hline $0-5$ & 6 & $1(16,7)$ & $1(16,7)$ & $0(0,0)$ & \\
$6-11$ & 35 & $3(8,6)$ & $2(5,7)$ & $1(2,9)$ & $6(17,1)$ \\
$12-17$ & 17 & $0(0,0)$ & $0(0,0)$ & $0(0,0)$ & $0(0,0)$ \\
$>17$ & 5 & $0(0,0)$ & $0(0,0)$ & $0(0,0)$ & $0(0,0)$ \\
\hline Total & 63 & $4(6,34)$ & $3(4,76)$ & $1(1,59)$ & $8(12,69)$ \\
\hline
\end{tabular}

Tabel 3. Prevalensi Infeksi Kecacingan STH Anak Panti Asuhan Berdasarkan Jenis Kelamin dan Lama Tinggal di Panti

\begin{tabular}{cccccc}
\hline \multirow{2}{*}{ Jenis Kelamin } & Jumlah & Jumlah Positif & & $\begin{array}{c}\text { Total } \\
(\boldsymbol{\%})\end{array}$ \\
\cline { 3 - 6 } & Sampel & $\begin{array}{c}\text { Ascaris } \\
\text { lumbricoides } \\
(\boldsymbol{\%})\end{array}$ & $\begin{array}{c}\text { Trichuris } \\
\text { trichiura } \\
(\boldsymbol{\%})\end{array}$ & Hookworm & \\
\hline Laki-Laki & 36 & $3(8,33)$ & $1(2,78)$ & $1(2,78)$ & $5(13,89)$ \\
Perempuan & 27 & $1(3,70)$ & $2(7,41)$ & $0(0,0)$ & $3(11,11)$ \\
\hline Total & 63 & $4(6,34)$ & $3(4,76)$ & $1(1,59)$ & $8(12,69)$ \\
\hline
\end{tabular}

Tabel 3 menunjukkan hasil prevalensi infeksi STH pada anak panti asuhan berdasarkan jenis kelamin yaitu laki-laki jumlah sampel yang diperiksa sebanyak 36 
(57,14\%) dengan jumlah infeksi STH sebanyak 5(13,89\%) dan jenis kelamin perempuan sebanyak $27(42,86 \%)$ yang diperiksa terdapat $3(11,11 \%)$ terinfeksi cacing STH.

Tabel 4. Hasil Analisis Hubungan Faktor Risiko Anak Panti Asuhan Terhadap Infeksi Kecacingan

\begin{tabular}{|c|c|c|c|c|c|c|}
\hline \multirow{2}{*}{ Faktor Risiko } & \multirow{2}{*}{$\mathrm{n}$} & \multicolumn{2}{|c|}{ Infeksi STH } & \multirow{2}{*}{ OR } & \multirow{2}{*}{$95 \% \mathrm{CI}$} & \multirow{2}{*}{ Nilai $\mathrm{p}$} \\
\hline & & Positif & Negatif & & & \\
\hline \multicolumn{7}{|l|}{ Kebiasaan Yang Dilakukan } \\
\hline Menggigit kuku jari tangan & 21 & $6(28.6)$ & $15(71.4)$ & 2.40 & $1.02-5.76$ & 0.04 \\
\hline Tidak Memotong Kuku & 18 & $5(27.8)$ & $13(72.2)$ & 1.30 & $0.24-6.79$ & 0.56 \\
\hline Mengisap jari kuku tangan & 14 & $4(28.6)$ & $10(71.4)$ & 5.40 & $0.47-296.03$ & 0.20 \\
\hline \multicolumn{7}{|l|}{ Menggunakan handuk bersama } \\
\hline Ya & 31 & $6(19.4)$ & $25(80.6)$ & 2.14 & $1.02-5.76$ & 0.028 \\
\hline Tidak & 32 & $2(6.3)$ & $30(93.8)$ & & & \\
\hline \multicolumn{7}{|l|}{ Kebersihan kuku } \\
\hline Ya & 17 & $2(11.8)$ & $15(88.2)$ & 0.74 & $5,399-49,507$ & 0.34 \\
\hline Tidak & 46 & $6(13.1)$ & $40(86.9)$ & & & \\
\hline \multicolumn{7}{|c|}{ Jumlah Mandi Setiap Hari (satu kali) } \\
\hline Ya & 27 & $4(14.8)$ & $23(85.2)$ & 0.55 & $3,772-17,62$ & 0.24 \\
\hline Tidak & 36 & $4(11.1)$ & $32(88.9)$ & & & \\
\hline \multicolumn{7}{|c|}{ Jumlah Mandi Setiap Hari (dua kali) } \\
\hline $\mathrm{Ya}$ & 37 & $3(8.1)$ & $34(91.9)$ & 0.55 & $3,772-17,62$ & 0.31 \\
\hline Tidak & 26 & $5(19.2)$ & $21(80.8)$ & & & \\
\hline \multicolumn{7}{|c|}{ Menggunakan alas kaki saat bermain } \\
\hline уа & 12 & $0(0.0)$ & $12(100)$ & 2.10 & $2,977-6,891$ & 0,042 \\
\hline Tidak & 51 & $8(15.7)$ & $44(86.3)$ & & & \\
\hline \multicolumn{7}{|c|}{ Menggunakan media tanah saat bermain } \\
\hline Ya & 54 & $8(14.8)$ & $46(85.2)$ & 16,34 & $5,399-49,507$ & 0,27 \\
\hline Tidak & 9 & $0(0.0)$ & $9(100)$ & & & \\
\hline \multicolumn{7}{|l|}{ Mencuci tangan sebelum makan } \\
\hline \multicolumn{7}{|l|}{ Dengan air saja } \\
\hline Ya & 20 & $1(5.0)$ & 19(95.0) & 8,15 & $3,772-17,62$ & 0,47 \\
\hline tidak & 43 & $7(16.3)$ & $36(83.70$ & & & \\
\hline \multicolumn{7}{|l|}{ Dengan air dan sabun } \\
\hline Ya & 8 & $0(0.0)$ & $8(100)$ & & & \\
\hline tidak & 55 & $8(14.5)$ & $47(85.5)$ & & & \\
\hline \multicolumn{7}{|c|}{$\begin{array}{l}\text { Mencuci tangan setelah buang air besar } \\
\text { (BAB) }\end{array}$} \\
\hline \multicolumn{7}{|l|}{ Dengan air saja } \\
\hline Ya & 59 & $7(11.9)$ & $52(88.1)$ & 4,092 & $2,706-6,188$ & 0,34 \\
\hline tidak & 4 & $1(25.0)$ & $3(75.0)$ & & & \\
\hline \multicolumn{7}{|l|}{ Dengan air dan sabun } \\
\hline $\mathrm{Ya}$ & 14 & $0(0.0)$ & $14(100)$ & & & \\
\hline tidak & 49 & $8(16.3)$ & $41(83.7)$ & & & \\
\hline
\end{tabular}

Sebanyak 21(33.3\%) anak memiliki kebiasaan menggigit kuku jari tangan dengan kejadian infeksi kecacingan sebanyak 6 (28.6\%) anak. Penggunaan handuk secara bersamasama yang dilakukan oleh anak panti asuhan sebanyak 31(49.2\%). Handuk ini biasanya dicuci sekali dalam setiap bulannya dan sebanyak 6(19.4\%) anak terinfeksi kecacingan usus 
STH. Faktor risiko perilaku lainnya yang diukur adalah tidak memotong kuku, kebiasaan mengisap kuku, tidak menggunakan alas kaki saat bermain sebanyak 51(80.9\%).

Analisis regresi ganda terhadap adanya infeksi maupun tidak terinfeksi telur cacing STH sebagai variabel dependent/terikat dengan variabel faktor risiko seperti menggunakan handuk secara bersama, kebiasaan menggigit kuku dan tidak mengunakan alas kaki saat bermain, frekuensi mandi tiap hari, praktek mencuci tangan sebelum dan sesudah makan sebagai variabel independent/bebas. Variabel faktor risiko yang berhubungan dengan infeksi STH yaitu kebiasaan menggigit kuku, tidak memakai alas kaki pada saat bermain dan kebiasaan menggunakan handuk secara bergantian dan bersama-sama dengan nilai $\mathrm{p}<0.05$ (Tabel 4).

\section{PEMBAHASAN}

Faktor risiko yang merupakan perilaku dan kebiasaan anak seperti mengisap jari kuku, menggigit kuku yang telah diamati pada anak-anak panti asuhan merupakan faktor risiko yang penting sehingga dapat mendorong terjadinya kontaminasi tanah oleh telur cacing sehingga dapat menyebabkan terjadinya penularan dari satu individu ke individu lain terutama pada anak-anak yang tinggal dalam suatu komunitas tertutup seperti panti asuhan atau lembaga kesejahteraan sosial anak (Nwaneri et al., 2013). Pada penelitian ini menunjukkan kebiasaan atau perilaku seperti menggigit kuku jari tangan, tidak memakai alas kaki saat bermain dan menggunakan handuk secara bersama-sama mempunyai hubungan yang signifikan antara anak yang terinfeksi cacing STH dari pada anak yang tidak terinfeksi cacing STH, sehingga anak-anak yang mempunyai kebiasaan tersebut dapat berpeluang dua kali atau lebih terinfeksi cacing usus STH dibandingkan anak yang tidak memiliki kebiasaan ini (Moffa et al., 2019). Penelitian ini juga sesuai dengan penelitian yang menyatakan perilaku dengan kebiasaan anak-anak tersebut merupakan faktor risiko yang signifikan pada anak yang terinfeksi cacing STH (Nwaneri et al., 2013).

Pada saat obeservasi penelitian hampir sebagian besar anak-anak memiliki kuku yang kotor dan panjang sehingga memungkinkan telur cacing menempel di bawah kuku jari sehingga terjadi penularan fecal-oral pada saat mengisap jari atau menggigit kuku. 
Penggunaan handuk secara bersama dan bergantian memberikan gambaran sebagai salah satu penyebab terjadinya penularan kecacingan pada orang ke orang (Du \& Vo, 2012) dan . Sebagian besar anak-anak di panti asuhan menggunakan handuk untuk mengeringkan badan setelah mandi. Handuk dapat merupakan sarana atau media perpindahan telur cacing dari satu orang keorang lain. Oleh sebab itu setiap anak di panti asuhan harus disediakan minimal satu handuk tiap anak kemudian dicuci secara teratur agar dapat mengurangi penularan infeksi cacing usus di panti asuhan (Du \& Vo, 2012)

Hasil penelitian ini menunjukkan prevalensi infeksi parasit usus secara keseluruhan pada anak panti asuhan tergolong rendah yang penelitian ditemukan juga oleh (Okpala et al., 2014), hal ini disebabkan selama peneltian dilakukan keadaan kurang lembab bahkan cenderung kering (Agustus-Oktober). Kondisi yang tidak mendukung seperti ini dapat memperngaruhi proses penetasan telur cacing sampai menjadi larva infektif (Zemene \& Shiferaw, 2018). Kondisi sanitasi yang lebih baik juga dapat menyebabkan rendahnya infeksi cacing usus pada anak (Maikaje \& Ijah, 2019). Pada masa pandemi Covid-19 sebagian besar anak dengan usia > 12 tahun telah mengikuti protokol kesehatan dengan mencuci tangan sebelum makan. Prevalensi infeksi kecacingan tertinggi pada kelompok usia 6-11 tahun beberapa pengasuh sulit mengendalikan kebiasaan anak-anak panti asuhan seperti tidak menggunakan alas kaki saat bermain, menggigit kuku dan menggunakan handuk secara bersama, beberapa penelitian telah melaporkan bahwa kebersihan pribadi yang rendah dan buruk merupakan faktor risiko utama terhadap kejadian infeksi kecacingan (Abebaw et al., 2020).

\section{KESIMPULAN}

Prevalensi infeksi kecacingan STH pada anak panti asuhan di Jayapura sebesar 12,69\% pada kelompok umur tertinggi 6-11 tahun dengan faktor risiko yang paling dominan yaitu tidak menggunakan alas kaki pada saat bermain, kebiasaan menggigit kuku jari tangan dan menggunakan handuk secara bersama-sama. 


\section{DAFTAR PUSTAKA}

Abebaw, A., Alemu, G., \& Ayehu, A. (2020). Prevalence of intestinal parasites and associated factors among children from child centres in Bahir Dar city, northwest Ethiopia. Tropical Doctor, 50(3), 194-198. https://doi.org/10.1177/0049475520920161

Bethony, J., Brooker, S., Albonico, M., Geiger, S. M., Loukas, A., Diemert, D., \& Hotez, P. J. (2006). Soil-transmitted helminth infections: ascariasis, trichuriasis, and hookworm. Lancet, 367(9521), 1521-1532. https://doi.org/10.1016/S0140-6736(06)68653-4

Du, N., \& Vo, O. (2012). Risks of intestinal helminthiasis in children living in orphanages in Benin city, Nigeria. Nigerian Journal of Paediatrics, 39(3), 118-123.

Healy, G. R. (1996). Bench Aids for the Diagnosis of Intestinal Parasites. In The American Journal of Tropical Medicine and Hygiene (Vol. 54, Issue 5). https://doi.org/10.4269/ajtmh.1996.54.5.tm0540050548a

Maikaje, D. B., \& Ijah, U. J. J. (2019). Prevalence of intestinal parasites among children attending daycare and orphanage centers in kaduna metropolis , kaduna. 14(3), 96-99.

Martila, M., Sandy, S., \& Paembonan, N. (2016). Hubungan Higiene Perorangan dengan Kejadian Kecacingan pada Murid SD Negeri Abe Pantai Jayapura. Jurnal Plasma, l(2). https://doi.org/10.22435/plasma.v1i2.4538.87-96

Moffa, M., Cronk, R., Fejfar, D., Dancausse, S., Padilla, L. A., \& Bartram, J. (2019). A systematic scoping review of hygiene behaviors and environmental health conditions in institutional care settings for orphaned and abandoned children. Science of the Total Environment, 658, 1161-1174. https://doi.org/10.1016/j.scitotenv.2018.12.286

Nwaneri, D. U., Ibadin, M. O., Ofovwe, G. E., \& Sadoh, A. E. (2013). Intestinal helminthiasis in children with chronic neurological disorders in Benin City, Nigeria: Intensity and behavioral risk factors. World Journal of Pediatrics, 9(2), 152-157. https://doi.org/10.1007/s12519-012-0394-9

Okpala, H. O., Josiah, S. J., Oranekwulu, M. U., \& Ovie, E. G. (2014). Prevalence of Intestinal Parasites among Children in Day Care Centres in Esan West Local Government Area, Edo State, Nigeria. Asian Journal of Medical Sciences, 6(4), 3439. https://doi.org/10.19026/ajms.6.4852

Sah, R. B., Bhattarai, S., Yadav, S., Baral, R., \& Jha, N. (2013). A study of prevalence of intestinal parasites and associated risk factors among the school children of Itahari , Eastern Region of Nepal. 3(2), 2-7. https://doi.org/10.4103/2229-5070.122143 
Waterston, T. (2011). Child health and the Arab spring. In Journal of Tropical Pediatrics (Vol. 57, Issue 4). https://doi.org/10.1093/tropej/fmr064

Zemene, T., \& Shiferaw, M. B. (2018). Prevalence of intestinal parasitic infections in children under the age of 5 years attending the Debre Birhan referral hospital, North Shoa, Ethiopia. BMC Research Notes, 11(1), 1-6. https://doi.org/10.1186/s13104-0183166-3 